AperTO - Archivio Istituzionale Open Access dell'Università di Torino

\title{
Future Perspectives in Nerve Repair and Regeneration
}

\section{This is the author's manuscript}

Original Citation:

Availability:

This version is available http://hdl.handle.net/2318/152010

since 2016-06-15T14:10:39Z

Publisher:

ELSEVIER ACADEMIC PRESS INC, 525 B STREET, SUITE 1900, SAN DIEGO, CA 92101-4495 USA

Published version:

DOI:10.1016/B978-0-12-420045-6.00008-0

Terms of use:

Open Access

Anyone can freely access the full text of works made available as "Open Access". Works made available under a Creative Commons license can be used according to the terms and conditions of said license. Use of all other works requires consent of the right holder (author or publisher) if not exempted from copyright protection by the applicable law. 


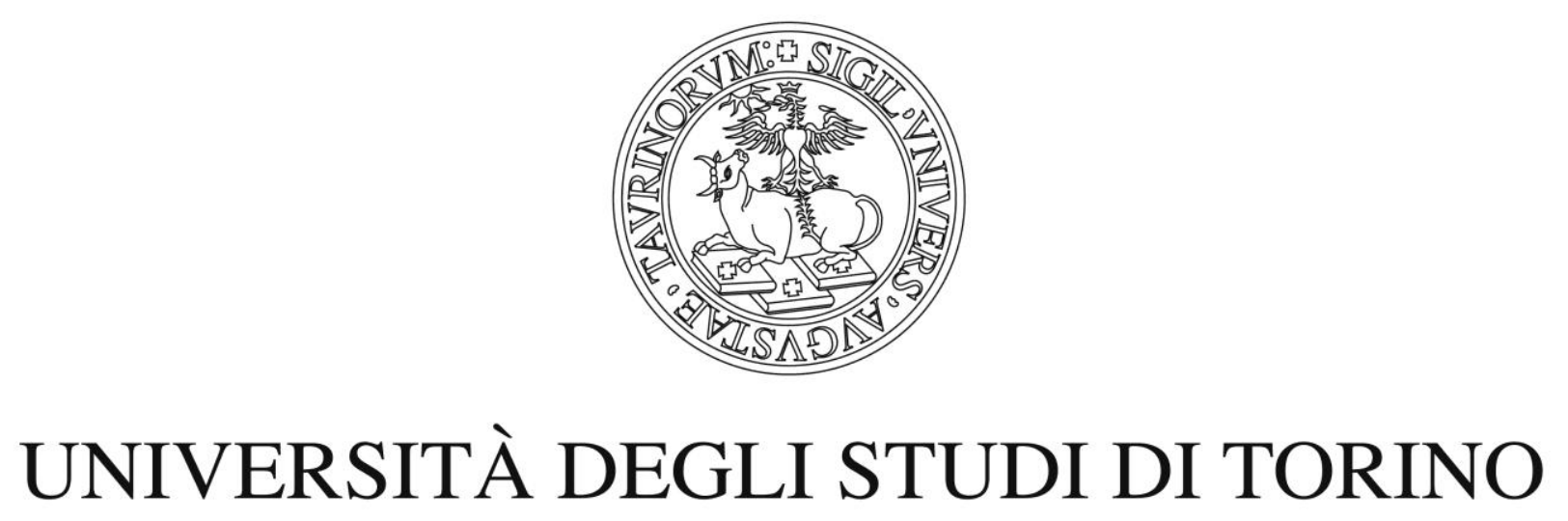

Thisis an authorversionof the contribution published on:

Questa è la versione dell'autore dell'opera:

Int Rev Neurobiol. 2013;109:165-92. doi: 10.1016/B978-0-12-420045-6.00008-0. Review.

The definitive version is available at:

La versione definitiva è disponibile alla URL:

http://www.sciencedirect.com/science/article/pii/B9780124200456000080 


\title{
Future Perspectives in Nerve Repair and Regeneration
}

Pierluigi Tos ${ }^{1}$, Giulia Ronchi ${ }^{2}$, Stefano Geuna ${ }^{2}$, Bruno Battiston ${ }^{1}$

1 Department of Traumatology, Microsurgery Unit, C.T.O. Hospital, Citta `della Scienza e della Salute, Turin, Italy 2 Department of Clinical and Biological Sciences, Neuroscience Institute of the Cavalieri Ottolenghi Foundation (NICO) University of Turin, Orbassano, Italy

\begin{abstract}
After peripheral nerve injuries, the process of nerve regeneration and target reinnervation is very complex and depends on many different events occurring not only at the lesion site but also proximally and distally to it. In spite of the recent scientific and technological advancements, the need to find out new strategies to improve clinical nerve repair and regeneration remains. To reach this goal, the therapeutic strategy shouldthusexertitseffectsatdifferentlevelsinordertosimultaneouslypotentiateaxonal regeneration, increase neuronal survival, modulate central reorganization, and inhibitorreducetargetorganatrophy.Itisexpectedthatthismultilevelapproachmight leadtosignificantimprovementinthefunctionaloutcomeandthusthequalityoflifeof the patients suffering from peripheral nerve injury.
\end{abstract}

\section{INTRODUCTION}

Peripheral nerve injuries belong to the most challenging and difficult surgical reconstructive problems, and often cause partial or total loss of motor, sensory, and autonomic functions. The consequences of nerves injuries, which occur in approximately $2.8 \%$ of trauma patients (Huelsenbeck et al., 2012), may be disastrous and can result in substantial functional loss, thus interfering with many aspects of a person's life because of permanently impaired sensory and motor functions. Moreover, development of secondary problems, such as neuropathic pain, dysesthesia, and cold intolerance is frequently observed following nerve injuries. In addition, nerve injuries have also a substantial economic impact on the society in terms of health care and long periods of sick leave (de Putter et al., 2012). Despite the ability of the peripheral nerve to regenerate and reinnervate denervated target organs has been recognized for more than a century, clinical and experimental evidences show that the regeneration is usually far from satisfactory, especially after severe injuries (Navarro, Vivo, \& Valero-Cabre, 2007; Pfister et al., 2011; Sun et al., 2009). So far, there is no technique to guarantee total recovery and normalization of functional sensibility following repair of an injured nerve. The poor outcome reflects the complexity of peripheral nerve injuries and the diversity of cellular and biochemical events, which are required to regain function. Indeed, a nerve injury differs from most other types of tissue injuries in the body, since it is not only a local repair process that is required. The processes of nerve regeneration and target reinnervation are complex, involving many factors which lead to immediate as well as long-term physiological, biochemical, and cellular changes (Fig. 8.1)(Lundborg, 2005). First of all, dramatic changes occur at the level of the damaged nerve (Geuna et al., 2009). After a peripheral nerve traumatic lesion, at the level of the nerve injury, changes begin almost immediately, both proximally and distally to the lesion. In the proximal segment, axons degenerate for some distancebackfromthesiteofinjury. Withinhours 
afterinjury,theaxonproduces a great number of collateral sprouts that advance distally. After nerve transection, the distal segment undergoes a slow process of degeneration known as Wallerian degeneration, which starts immediately after injury and involves myelin breakdown and proliferation of Schwann cells. Schwann cells and macrophages are recruited to the injury site and phagocytize all the myelin and cellular debris. As the axon sprouts from the proximal stump, they regenerate between the layers of basal lamina of the Schwann cell processes reaching finally the target organs (Geuna et al., 2009). Second, changes occur to the target organ innervated by the damaged nerve (Geuna et al., 2009). The regenerated axon must reinnervate the proper target, and the target must retain the ability to accept reinnervation and recover from denervationrelated atrophy. Regeneration rate is approximately $1 / 2 \mathrm{~mm} /$ day; therefore, more proximal injuries lead to longer denervation periods and, despite optimal microsurgical techniques, the functional results achieved after repair of severed peripheral nerves are much less than optimal due to the target organ atrophy that takes place during the period of denervation. Third, changes occur to the proximal neural structures (e.g., dorsal root ganglia and spinal cord) where the cell bodies of the neurons are located. As a consequence of peripheral nerve injury, cell bodies in dorsal root ganglia (DRGs) and anterior horns of the spinal cord undergo adaptive changes that involve a chromatolytic reaction associated with a shift in protein synthesis from a "signaling mode" to a "growing mode" and protein synthesis switches from neurotransmitter-related substances to those required for axonal reconstruction. Moreover, the peripheral and central nervous systems (CNSs) are functionally integrated and a peripheral nerve lesion always results in long-lasting central modifications and reorganization (Kaas, 1991; Kaas \& Collins, 2003; Wall, Xu, \& Wang, 2002). The mechanisms of plasticity and reorganization of brain circuits that occur after nerve injury are complex; they may result in beneficial adaptive functional changes or contrarily cause maladaptive changes, such as pain, dysesthesia, hyperreflexia, and dystonia (Lundborg, 2000, 2003).

\section{CHANGES AT THE NERVE LEVEL}

In 1943, Sir Herbert Seddon introduced a classification of three discrete types of nerve injury: neurapraxia, axonotmesis, and neurotmesis (Seddon, 1943): i. Neurapraxia is a mild injury characterized by local myelin damage. Axon continuity is preserved, and the nerve does not undergo Wallerian degeneration. It may result from exposure to a wide range of conditions such as heat, cold, irradiation, or electrical injuries, but is most commonly due to mechanical stress, such as concussion, compression, or traction injuries. Recovery may occur within hours, days, weeks, or up to a few months. ii. Axonotmesis involves additional damage to peripheral axons, but connective tissue structures remain intact. The interruption of axons is often the result of nerve pinching, crushing, or prolonged pressure. Wallerian degeneration occurs, but subsequent axonal regrowth may proceed along the intact endoneurial tubes. Recovery depends upon the degree of internal disorganization in the nerve aswell as the distance to the end organ. iii. Neurotmesis is the most severe injury, equivalent to physiologic disruption of the entire nerve. Functional recovery does not easily occur because of the extent of endoneurial tube disruption. Nonetheless, successful regeneration might result with surgical intervention. In 1951, Sunderland expanded Seddon's classification to five degrees of peripheral nerve injury instead of three (Sunderland, 
1951). He divided Seddon's axonotmesis grade into three types, depending on the degree of connective tissue involvement:

i. Type 1 injury corresponds to Seddon's neurapraxia with conduction block and completely intact stroma.

ii. Type 2 injury corresponds to Seddon's axonotmesis. The endoneurium, perineurium, and epineurium are still intact, but the axons are physiologically disrupted. Recovery can occur by axonal regrowth along endoneurial tubes, and complete functional recovery can be expected. The time for recovery depends on the level of injury, usually months.

iii. In type 3 injury, the endoneurium is also disrupted, but the surrounding perineurium and epineurium are intact. Recovery is incomplete and depends upon how well the axons can cross the site of the lesion and find endoneurial tubes.

iv. In type 4 injury, individual nerve fascicles are transected, and the continuity of the nerve trunk is maintained only by the surrounding epineurium. This type of injury requires surgical repair or reconstruction of the nerve.

v. Type 5 injury is equivalent to Seddon's neurotmesis (complete nerve disruption), and spontaneous recovery is negligible. Although Sunderland's classification provides a concise and anatomic descriptionofnerve injury, the clinicalutility ofthis systemisdebatable since a nerve may undergo a combination of different degrees of injury. Therefore, a sixth degree of nerve injury has been introduced to define a combination of the other degrees of injuries (Mackinnon, 1989). After a peripheral nerve traumatic injury, complex pathophysiologic changes, including morphologic and metabolic changes, occur at the injury site almost immediately. The interruption of a peripheral nerve causes significant changes in normal morphology and tissue organization both proximally and distally to the lesion site. Thenervestumpdistaltothelesionundergoesadegenerationthatisnow known as "Wallerian degeneration" in honor of Augustus Volney Waller, who first characterized the disintegration of the frog glossopharyngeal and hypoglossal nerves after axotomy 160 years ago (Stoll, Jander, \& Myers, 2002). The process involves a number of phases, some concurrent, others consecutive, in which the distal portions of all affected axons degenerate. The sequence begins with prompt degradation of axoplasm, axolemma, and myelin sheath due to proteolysis (Lubinska, 1982; Schlaepfer, 1977; Vial, 1958). Then, the degraded myelin is phagocytized by the recruited macrophages to aid the removal of axonal and myelin debris (Bruck, 1997; Vargas \& Barres, 2007). Fragmentation of axons is first detected few hours after nerve transection. Within $48 \mathrm{~h}$, the entire nerve is fully involved, and over a period of 3-6 weeks, Schwann cells and macrophages phagocytize all the myelin and cellular debris. Schwann cells play several important roles in nerve degeneration and regeneration:

i. Coincident with axonal injury, Schwann cells in the distal nerve begin to dedifferentiate (Lee et al., 2009). Within $48 \mathrm{~h}$ of injury, they start altering their gene expression: expression of myelin proteins (e.g., PO, MAG (myelinassociated glycoprotein)) (Trapp, Hauer, \& Lemke, 1988; White et al., 1989) and connexin 32 (a gap junction protein which forms reflexive contacts within 
individual myelinating SCs at para-nodes) (Hall, 2001) decreases dramatically as a consequence of axonal degeneration distal to the injury site, whereas regeneration associated genes (GAP-43), neurotrophic factors and their receptors, neurotrophin 4/5 (NT-4/5) neuregulin and its receptors, including the low-affinity neurotrophin receptor p75NTR; nerve growth factor (NGF), brainderived neurotrophic factor (BDNF), glial cell linederived neurotrophic factor (GDNF), and insulin-like growth factors (IGFs) (Carroll, Miller, Frohnert, Kim, \& Corbett, 1997; Hall, 2001) are upregulated.

ii. Between days 1 and 5 after injury, Schwann cells start proliferating, a critical event for the promotion of axonal regeneration. Their peak of activation occurs around day 3 postinjury and then decreases during the following weeks. A second phase of proliferation occurs during the regenerative process. Proliferating Schwann cells align in columns known as bands of $\mathrm{Bu}$ "ngner, which provide a supportive substrate and growth factors for regenerating axons (Griffin \& Thompson, 2008; Stoll, Griffin, Li, \& Trapp, 1989).

iii. Schwann cells also play an important role in removing myelin debris; rapid clearance of myelin appears to be the most important precondition for axonal regeneration after peripheral nerve injury because it contains molecules that are inhibitory to axonal growth, such as MAG and oligodendrocyte-myelin glycoprotein (Huang et al., 2005; Shen et al., 2000). iv. Yet, Schwann cells in the distal nerve stump produce several neurotrophic and neurotropic molecules (such as NGF, BDNF, NT-4, GDNF, and insulin-like growth factor-1 (IGF-1)) that promote axon growth (Chen, Yu, \& Strickland, 2007). Moreover, denervated Schwann cells overexpress fibronectin, laminin, tenascin, and some proteoglycans, whichcreatea substratefor axonal elongation. The phenotype of reactive Schwann cells resembles the one of immature Schwann cells, and they form a permissive substrate for regeneration. When these cells regain contact with the axons, they redifferentiate again (Jessen \& Mirsky, 2008).

Wallerian degeneration represents the basis for the nerve regeneration and target reinnervation processes (Battiston, Geuna, Ferrero, \& Tos, 2005; Schmidt \& Leach, 2003; Terzis, Sun, \& Thanos, 1997). In severe injuries, nerve regeneration begins only after Wallerian degeneration has run its course, but in mild injuries, the regenerative and repair processes begin almost immediately. The rate of axonal regrowth is determined by changes within the cell body, the activity of the specialized growth cone at the tip of each axon sprout, and the resistance of the injured tissue between cell body and end organ. Regenerating axons are usually produced at the node of Ranvier located close to the proximal stump of the lesion (Hopkins \& Slack, 1981; McQuarrie, 1985). Nodal sprouts usually contain vesicles of various sizes, and as the sprouts develop into well-formed growth cones, the number of vesicles markedly increases. Sprouts from the node of Ranvier extend through their own basal lamina tubes in the proximal segment, traverse the narrow gap of connective tissue between the proximal and distal stumps, and finally enter the distal nerve segment. During extension through the Schwann cell column, regenerating axons grow along the Schwann cell basal lamina. Axon-Schwann cell attachment is mediated by various adhesion 
molecules including the immunoglobulin superfamily, for example, neural cell adhesion molecule ( $\mathrm{N}-\mathrm{CAM}$ ) and $\mathrm{L} 1$, and the cadherin superfamily, for example, $\mathrm{N}$-cadherin and E-cadherin, whereas axon basal lamina contact is for the most part mediated by laminin (Letourneau, Condic, \& Snow, 1994). These adhesion molecules are no longer detected when Schwann cells begin to form the myelin sheath around the axon, whereas the mature unmyelinated fibers continue to exhibit such adhesion molecules (Ide, 1996). When surgical repair of the nerve is required, the goal is to guide regenerating sensory, motor, and autonomic axons to the distal nerve segment to maximize the chance of target reinnervation (Pfister et al., 2011). Nerve reconstruction by tissue engineering has seen an increasing interest over the past years (Leach \& Schmidt, 2005; Pfister et al., 2011). Despite the spontaneous regeneration potential of peripheral nerves and the best efforts and modern surgical techniques, functional restoration is often incomplete and clinical results are still unsatisfactory (Battiston et al., 2009; Scholz et al., 2009). Peripheral nerve injury may result in injury without gaps or injury with gaps between the nerve stumps. When there is no gap or the gap is short ( $5 \mathrm{~mm}$ or less), as in simple injuries, the common surgical approach is a direct suture of the two stumps (end-to-end suture) (Terzis et al., 1997). For longer nerve gaps, when nerve injury resulted in substance loss between the two nerve stumps, this direct suturing under tension leads to very poor clinical results (Dvali \& Mackinnon, 2003) and a segment of nerve or other materials must be used to bridge the gap. The demonstration, in the early 1970s, that grafting of an autogenous nerve segment to bridge a nerve defect leads to better clinical results than suturing the two stumps under tension (Millesi, 1970), opened a new era in peripheral nerve surgery making it possibly the most successful surgical approach to complex lesions that before would have been unfathomable. There are three types of conventional bridging materials:

i. Autologous nerve grafts. Nerve autografts have seen extensive clinical employment over the past 30 years. A nerve graft providesan ideal conduit for regenerating axons because it provides a scaffold which contains Schwann cell basal laminae, and moreover, these Schwann cells produce growth factors (Lundborg, 2004). Autogenous nerve grafting can be performed with nonvascularized autogenous nerve, vascularized nerve, interpositional conduits, and nerve allografts. However, it has several disadvantages, including an extra incision for the removal of a healthy sensory nerve, and the removal of a healthy sensory nerve whichwill result ina sensory deficit. Finally, donorgraft material islimited, particularly for managing extensive lesions which require several lengths of nerve graft.

ii. Non-nervous biological grafts. Conduits made by small segments of an artery were first successfully employed by Bungner (Bungner, 1891). However, interest shifted then to veins for their larger availability and reduced side effects related to their withdrawal (Wrede, 1909). Similartoveins,alsotheuseofskeletalmuscleautograftsfornerverepair wasalready reported many years ago (Fawcett \& Keynes, 1990; Keynes, Hopkins, \& Huang, 1984). The idea of employing muscle fibers for axonal regeneration is on the similarities between the muscle basal lamina and the endoneurial tubes (Fawcett \& Keynes, 1990; Glasby, Gschmeissner, Hitchcock, \& Huang, 1986). Finally, a combined conduit by enriching vein segments with fresh skeletal muscle fibers (muscle-in-vein conduit) is used to improve effectiveness of tubulization nerve repair (Battiston, Tos, 
Cushway, \& Geuna, 2000; Battiston, Tos, Geuna, Giacobini-Robecchi, \& Guglielmone, 2000; Brunelli, Battiston, Vigasio, Brunelli, \& Marocolo, 1993; Fornaro, Tos, Geuna, Giacobini-Robecchi, \& Battiston, 2001; Tos, Battiston, Ciclamini, Geuna, \& Artiaco, 2012).

iii. Non-biological grafts. The use of non-biological materials for nerve reconstruction has a lengthy history started at the beginning of the twentieth century, and many attempts to use various nonbiological materials, such as metals, permeable cellulose esters, gelatine tubes, rubber, plastics, etc., were carried out (Fields, Le Beau, Longo, \& Ellisman, 1989). The past 30 years saw an impressive increase of experimental studies aimed at testing new biomaterials for nerve regeneration, such as decalcified silicone tube, bone tube, nylon fiber tube, polyurethanes, etc.(Battistonet al., 2005; Pfister, Papaloizos, Merkle, \&Gander,2007; Schmidt \& Leach, 2003). The results have been in general very successful, and their effectiveness is similar and sometimes even superior to traditional nerve autografts (Navarro et al., 1996; Yannas \& Hill, 2004; Young, Wiberg, \& Terenghi, 2002).

Moreover, direct neurotization of denervated muscles is used in situations where the motor nerve has been avulsed and direct nerve suture or grafting is not possible (Brunelli, 2005). It has been demonstrated that an axon that is in contact with a denervated muscular fiber can form a new neuromuscular junction (NMJ). A prerequisite for this procedure is that there is some residual trophism of the muscle. Generally, however, neurotization procedures have poor functional outcome. Finally, end-to-side neurorrhaphy is based on the assumption that an intact nerve can "donate" axons to the distal end of an injured nerve (Papalia et al., 2003). This technique has received particular interest when the nerve gap is large or when the lesion is proximal, both of which severely limit nerve regeneration.

\section{CHANGES OCCURRING DISTALLY TO THE DAMAGED NERVE: FOCUS ON SKELETAL MUSCLE}

Target organ atrophy might represent a limiting factor in functional recovery after nerve repair and regeneration. Among the different sensory and motor target organs, skeletal muscles represent the most important ones in terms of clinical relevance. The normal structural and functional integrity of skeletal muscle depends on intact innervation, normal transmission of impulses across the myoneural junction, and normal metabolic processes within the muscle cell. Injury to peripheral nerves always results in immediate loss of muscle function and progressive skeletal muscle atrophy, thus representing an important cause of poor clinical results after nerve reconstruction. Following a peripheral nerve injury, the longer the interval between denervation and reinnervation, the poorer the degree of motor recovery; thus, the regenerative outcome may be very poor when reinnervation of denervated target organs is delayed due either to a long distance between target and lesion site or to delayed nerve repair following major trauma (Birch \& Raji, 1991; Merle, Bour, Foucher, \& Saint Laurent, 1986). Since axons usually regrow at an average rate of $1 \mathrm{~mm} /$ day (Buchthal \& Kuhl, 1979; Seddon \& Fynn, 1972), it would take a long time for the muscle to be reinnervated. The success of reinnervation depends therefore both on the ability of the neuron to reprogram its growth and to establish new connections, and on the ability of muscle fibers to survive in the absence of trophic and regulating signals derived from the nerve. 
Denervated muscles come across structural, biochemical, and physiological changes eventually leading to atrophy and apoptosis, losing up to $80 \%$ of their mass (Gutmann, 1962). Over time, denervated muscles lose receptiveness to regenerated motor axons that reach the muscle because of a significant loss of viable muscle cells due to fiber necrosis, connective tissue hyperplasia, and exhaustion of satellite cell regeneration (Fu \& Gordon, 1995; Irintchev, Draguhn, \& Wernig, 1990; Schmalbruch, al-Amood, \& Lewis, 1991; Veltri, Kwiecien, Minet, Fahnestock, \& Bain, 2005). The loss of neural input, including neurotransmitters, neurotrophic factors, and other signals, promotes muscle fiber atrophy and thus reduces receptivity to regenerated axons (Veltri et al., 2005). Moreover, in response to an injury, satellite cells undergo a period of rapid proliferation; the majority of the satellite cells differentiate and fuse to form new myofibers or to repair the damagedones(Lu,Huang,\&Carlson,1997;Schultz, Jaryszak,\&Valliere,1985). During early stages, denervated muscle shows also a wide spectrum of molecular and cellular changes, including changes in gene expression. Upon denervation, there is the upregulation of NGF, BDNF (Zhao, Veltri, Li, Bain, \& Fahnestock, 2004), IGF (Tang, Cheung, Ip, \& Ip, 2000), fibroblast growth factor (FGF), hepatocyte growth factor (Yamaguchi, Ishii, Morita, Oota, \& Takeda, 2004), and the alpha component of ciliary neurotrophic factor (CNTF) receptor complex (Tang et al., 2000). Also, the expression of many metabolic molecules, such as ferritin heavy chain, adhesion molecules, such as N-CAM, and extracellular proteases, including urokinase, change in response to muscle denervation. Finally, an increase in the level of ErbB2 and ErbB3 receptors and Neuregulin1 expression was also demonstrated (Ng, Pun, Yang, Ip, \& Tsim, 1997; Nicolino et al., 2009; Suarez et al., 2001). These adaptive changes might act to maintain muscle fiber survival during early stages of denervation and participate in the remodeling of neuromuscular synapse (Tang et al., 2000). Traditional strategies to improve motor functional recovery after injury by delaying the effects of the denervation process include electrical stimulation and rehabilitation of the denervated muscles (Nicolaidis \& Williams, 2001). These treatments can improve muscle function after nerve injury in the clinical setting; however, they are not very effective in arresting denervated muscle atrophy and patient compliance is often poor; moreover, implantable electrical systems are expensive. Microsurgical repair within 2 months of injury can essentially reverse skeletal muscle changes and result in good functional recovery (Finkelstein, Dooley, \& Luff, 1993). In contrast, if surgery is delayed for 6 months or more, denervation results in irreversible structural damage, including extrafusal fiber necrosis, connective tissue hyperplasia, and deterioration of the muscle spindles, leading to poor reinnervation and functional recovery (Bain, Veltri, Chamberlain, \& Fahnestock, 2001; Hynes, Bain, Thoma, Veltri, \& Maguire, 1997; Veltri et al., 2005). Furthermore, even when nerve surgery is performed early, there will still be a long period of muscle denervation if the distance from the site of injury is substantial, and the operative results are likely to be correspondingly poor. Auseful strategy to delay the skeletal muscle atrophy might be toconnect the end of a sensory nerve to the side of the distal nerve stump of the injured nerve (sensory protection) in order to maintain the structural and functional integrity of muscle until axons of the native nerve reach their target (Bain et al., 2001; Hynes et al., 1997; Irintchev et al., 1990; Veltri et al., 2005; Wang, Gu, Xu, Shen, \& Li, 2001). This strategy uses a readily available sensory nerve to directly or indirectly support denervated muscle fibers by the supply of trophic factors, improve existing endoneurial sheath structure, and enhance regeneration by the native nerve (Veltri et al., 
2005; Zhao et al., 2004). It has been shown that sensory protection minimizes two of the three major structural consequences of chronic denervation: fiber necrosis and connective tissue hyperplasia.

Anothersolutiontodelaythedenervatedatrophyofskeletalmusclesisthe use of neural stem cells (NSCs); recent studies have reported that genetically modified NSCs ameliorate experimental spinal muscular atrophy, providing neurotrophic support or partially replacing interrupted innervation between neural cells and skeletal muscles (Corti et al., 2006, 2009). Embryonic stem cellstransplantedintothespinalcordcoulddifferentiateintorelativelynormal motor neurons, extend axons into periphery nerves, and form new NMJs with denervated muscles (Deshpande et al., 2006; Gao, Coggeshall, Tarasenko,\&Wu,2005;Lee,Tos,etal., 2007;Lee,Jeyakumar,etal.,2007). Finally, local and/or systemic administration of various molecules might also prevent skeletal muscle atrophy, such as IGF-1 (Latres et al., 2005; Yoshida, Semprun-Prieto, Sukhanov, \& Delafontaine, 2010) and ghrelin (Porporato et al., 2013).

\section{CHANGES OCCURRING PROXIMALLY TO THE DAMAGED NERVE}

\subsection{Changes in the DRGs after peripheral nerve injury and regeneration}

Anatomically, the DRGs are located along the dorsal spinal roots; they house the cell bodies of primary afferents of the spinal sensory system and are surrounded by a thick connective capsule. As a consequence of a peripheral nerve injury, trophic support from the periphery is blocked and DRG neuron cell bodies undergo adaptive changes: Nissl bodies (i.e., the basophilic neurotransmitter synthetic machinery) undergo dissolution, which is followed by a prominent migration of the nucleus from the center of the cell toward the periphery, an increase in the size of the nucleolus, nucleus, and cell body, cell swelling, and retraction of dendrites, which collectively are called "chromatolytic changes" (Fenrich \& Gordon, 2004; Lieberman, 1971). The disappearance of the prominent basophilic-stained Nissl granules is particularly evident. These granules are ribosome clusters of rough endoplasmic reticulum, that is not observed after axotomy, when they become disorganized, freeing polyribosomes and ribonucleotides into the cytoplasm. The severity and the time course of the chromatolytic process are mainly influenced by the severity of the injury, the distance of lesion to cell body, the type of neuron, and the age (Navarro et al., 2007). The dissolution of the ribosomes and ordered arrays of rough endoplasmic reticulum that constitute the Nissl bodies are then accompanied by metabolic changes including overall increases in protein and mRNA synthesis as well as changes in the pattern genes that the neuron expresses. The main metabolic activity of the cell is shifted from synthesizing neurotransmitterrelated proteins to the synthesis of structural materials needed for axon repair and growth. For example, choline acetyltransferase is downregulated, whereas the neuropeptide, calcitonin gene-related peptide, the fast transported growth-associated protein, GAP-43, and the slowly transported cytoskeletal proteins, actin and tubulin, are upregulated (Haas, Donath, \& Kreutzberg, 1993; Tetzlaff, Gilad, Leonard, Bisby, \& Gilad, 1988). Glucose-6-phosphate dehydrogenase and hydrolytic enzyme are also upregulated (Davis, Taylor, \& Anastakis, 2011; Fawcett \& Keynes, 1990). The success of nerve regeneration and functional reinnervation of 
targets first depend on the capacity of axotomized neurons to survive and shift toward the regenerative phenotype (Navarro et al., 2007). Results of studies on the changes in DRG neuron number following a nerve injury show a wide variation in results. Most of the authors report that peripheral nerve transection induces the primary sensory neuronal death (Himes \& Tessler, 1989; Terenghi, 1999; Vestergaard, Tandrup, \& Jakobsen, 1997), showing that between $7 \%$ and $50 \%$ of primary sensory neurons (more small than large neurons) die after injury (Himes \& Tessler, 1989; McKay Hart, Brannstrom, Wiberg, \& Terenghi, 2002). Other authors report no significant neuron loss (Swett, Hong,\& Miller,1995) orno detectable lossof dorsalroot axons until 4 months (Coggeshall, Lekan, Doubell, Allchorne, \& Woolf, 1997; Cohen, Yachnis, Arai, Davis, \& Scherer, 1992) after injury to the spinal or sciatic nerve. Further, during regeneration, the cell body undergoes visible changes that mark the reversal of chromatolysis. Indeed, the nucleus returns to the cell center and nucleoproteins reorganize into the compact Nissl granules. Acomplex andincompletely understoodinteraction occursbetweenthe cell body and the regenerating axon tip. Axoplasm, which serves to regenerate the axon tip, arises from the proximal axon segment and cell body. Both fast and slow components of axoplasmic transport supply materials from the cell body to the sites of axonal regeneration. The rate of increase in protein and lipid synthesis in the cell body influences the rate of advance and the final caliber of the regenerating axon (Burnett \& Zager, 2004).

\subsection{CNS plasticity induced by peripheral nerve injury and regeneration}

Until recently, it was thought that no new neural connections could be formed in the adult brain (Kandel \& Squire, 2000). It was assumed that, once connections had been established in foetal life, they hardly changed in adulthood. The only areas of the adult brain capable of reorganization were those involved in learning and memory processes. The picture has changed radically in the past decades; indeed, recent evidence demonstrates that the brain is capable of remarkable and widespread adaptive changes in response to peripheral injuries (Davis et al., 2011; Jain, Florence, \& Kaas, 1998; Navarro et al., 2007). In fact, an injured nerve stops to function normally and this occurrence results in the reorganization of the projections to the CNS. While it is likely that this reorganization following injury takes place in the cortex, plastic changes may also occur in subcortical structures such as the thalamus, brainstem relay nuclei, and spinal cord (Lewin \& McMahon, 1993). Plasticity of central connections may be positive, that is, compensate the lack in target reinnervation, but may also result in maladaptive changes, such as neuropathic pain, hyperreflexia, dystonia, and phantom limb awareness (Navarro et al., 2007). The response of the CNS to altered peripheral inputs may take many forms and include changes in ongoing or stimulusevoked activity, neurochemical changes, functional alterations of excitatory and inhibitory connections, atrophy and degeneration of normal substrates, sprouting of new connections, and reorganization of somatosensory and motor maps (Davis et al., 2011; Navarro et al., 2007). Plasticity of the somatosensory system has been extensively studied, and it has been shown that dramatic changes in the organization of cortical topography of the S1 area (primary somatosensory cortex) occur in response to a peripheral nerve injury (Donoghue \& Sanes, 1987). It has been demonstrated that following peripheral nerve lesion in adult monkeys, the area in the somatosensory cortex corresponding to the deafferented body parts of the S1 became 
responsiveto inputs from neighboring body parts (Merzenich et al., 1983). Although this form of cortical plasticity is well documented across several sensory systems and in several species, such as cats, raccoons, rodents, and bats, the understanding of the underlying mechanisms remains an active area of research (Pelled, Chuang, Dodd, \& Koretsky, 2007). In the motor system, changes in cortical representation also occur after peripheral injury; following amputation or peripheral nerve lesions, the area from which stimulation evoked movements of the adjacent body parts enlarged and the threshold for eliciting these movements is reduced (Donoghue \& Sanes, 1988; Sanes, Suner, \& Donoghue, 1990). The hypothesis that also visceral afferents exert a significant influence on the CNS plasticity has been investigated by many researchers, even if little is known. Recent studies have showed that vagus nerve stimulation (VNS, a well-established adjunctive treatment for intractable epilepsy and treatmentresistant depression) can induce neurogenesis andplasticityin the hippocampus (Biggio et al., 2009). In particular, it was demonstrated that acute VNS induces cell proliferation in the dentate gyrus of the adult rat hippocampus and an increase of both the total amount of doublecortin (DCX) immunoreactivity and the number of DCX-positive neurons in the dentate gyrus. In contrast, chronic VNS induced an increase of the BDNF expression, which may serve to promote and maintain new neuronal connections formed in response to chronic VNS (Biggio et al., 2009). Moreover, it was shown that acute VNS increased the expression ofgenes for BDNFand basic FGF in the rat hippocampus, both of which are important modulators of hippocampal plasticity and neurogenesis (Follesa et al., 2007). Finally, a recent study showed that damage to the subdiaphragmatic vagus in adult rats is followed by microglia activation and long-lasting changes in the dentate gyrus, leading to alteration of neurogenesis (Ronchi, Ryu, Fornaro, \& Czaja, 2012).

\section{HOWTOSTUDYPERIPHERALNERVEREGENERATION?}

Essential progress in peripheral nerve regeneration research has been possible using animal models which may simulate anatomical, physiological, and behavioral aspects of the regenerative process. The experimental models available can be divided into three main groups according to (i) the animal model, (ii) the localization of lesion, and (iii) the type of lesion. By far, in nerve regeneration studies, the most employed laboratory animals are rats. The main reason appears to be the larger physical size of rat nerves compared to mouse nerves, which reduces the complexity of the microsurgical procedures (Tos et al., 2008), the possibility to have standardized and comparable functional tests and the fact that rats are more resilient than mice. On the other hand, the availability of genetically modified mouse colonies will probably increase mouse employment since transgenic models will allow to elucidate the role of a particular gene or protein in the mechanisms of the nerve regeneration process. In addition to these models, various large animal models have been employed including rabbits, sheep, pigs, and primates because several authors believe that the translation to clinical application may benefit from a preclinical study on large animal nerves since the regeneration process of nerves in large animals is more similar to humans (Fullarton, Lenihan, Myles, \& Glasby, 2000). Accordingtothelocalizationofthelesion, untilrecently, mostperipheral nerveregenerationstudieshadbeenmainlycarriedoutontheratsciaticnerve model, primarily because 
it is the largest peripheral nerve (Baptista et al., 2007; Luis et al., 2007; Varejao et al., 2004). However, since most of the human peripheral nerve injuries affect the upper extremity, the necessity ofanexperimentalmodelclosertoclinicalinterestsisrequired.Indeed, recent years have shown an increasing interest toward the employment of major forelimb nerves (Geuna et al., 2007; Papalia, Tos, Scevola, Raimondo, \& Geuna, 2006; Papalia, Tos, Stagno d'Alcontres, Battiston, \& Geuna, 2003; Sinis et al., 2008; Tos et al., 2009). In particular, the median nerve attracted the attention of peripheral nerve researchers because of the availability of an easier and more reliable behavioral test (the grasping test) (Lee, Tos, et al., 2007; Papalia et al., 2003; Tos et al., 2007). According to the type of lesion, so far, two main experimental lesion paradigms have been adopted for nerve regeneration studies: (1) axonotmesis (crush), which is characterized by complete interruption of nerve fibers continuity without discontinuingthe nerve, and(2) neurotmesis, which is a complete transection of the whole nerve. The complete nerve transection requires surgicalrepairtoreestablishepineurialcontinuity.Thisexperimentalparadigm provides not only the model for the comparative investigation of new types of microsurgical and tissue engineering approaches for nerve reconstruction but also a good model for assessing the effectiveness of various postoperative treatments (drugs, physical therapy, diet, etc.). On the other hand, with a crush lesion, the injured axons are provided with an optimal regeneration pathway, represented bythenerve segmentdistal totheinjury,without the need for the microsurgical repair. This experimental approach is therefore less technically challenging and is particularly suitable when a reproducible regeneration process is required, such as for the study of the biological mechanisms of regeneration or rationale development for new therapeutic agents. Recent advances in molecular neurobiology include the development of transgenic mice that have been used in multiple areas, including the field of developmental neurobiology and disease processes such as cancer and diabetes, but their use has extended also to the study of peripheral nerve regeneration subsequent to traumatic injuries. In particular, knockout mice, which carry a targeted gene inactivated through genetic engineering, are useful to elucidate the role of a particular gene or protein in a physiologic pathway by evaluating the consequences of its inactivation. On the other hand, transgenic animals that overexpress a particular gene or proteins are available, thus circumventing methodological difficulties in drug delivery, maintenance of constant neurotrophic factor concentrations, and the comorbidities associated with achieving these aims. Moreover, the availability of conditional knockout mice whose mutations can be targeted both spatially and temporally obviate the problem that some homozygous knockout mice can be embryonically lethal, thus limiting their usefulness. In addition, emerging tools include mice the axons or Schwann cells of which express fluorescent chromophores, which enabled new experiments with direct visualization of nerve regeneration over time. Inthe past years, many studiesof peripheralnerve regeneration have used knockout animals to elucidate the role of different neurotrophic factors during the process. For example, it has been shown that animals lacking CNTF are unable to produce motor nerve terminal sprouts after nerve transection or botulinum toxin injection and have also decreased ability to repair peripheral nerve damage from crush injury (Mizisin, Vu, Shuff, \& Calcutt, 2004). Studies using GDNF-deficient mice, as well as NT3 deficient mice, revealed inadequate development of sympathetic and sensory neurons (Anand, 2004), whereas knockout animals for the low-affinity NGF receptor p75NGFR showed decreased 
sensory innervation (Lee et al., 1992). Transgenic mice lacking IGF-1 show a decrease in motor and sensory nerve conduction velocities but no significant reduction in peripheral nerve myelination (Gao et al., 1998). Animals lacking ApoD revealed a decrease in motor nerve conduction velocityandthicknessofmyelinsheathinintactnerves, andafterinjury, axon regeneration and remyelination are delayed (Ganfornina et al., 2010). The lackofCx32,agapjunctionprotein, showedabnormallythinmyelinsheaths, reflecting myelin degeneration-induced Schwann cell proliferation, while nerve conductance properties are altered only slightly (Anzini et al., 1997). Neuropilin-2-deficient mice showed slower axonal regeneration, remyelination of the regenerating axons, and recovery of normal gait after a crush lesion of the sciatic nerve (Bannerman et al., 2008). An experiment using the Cre-loxP system to disrupt the laminin g1gene in Schwann cells showed that, during development, Schwann cells that lack laminin g1 were unabletodifferentiateandsynthesizemyelinproteins, andthereforeunableto myelinate axons. Moreover, after sciatic nerve crush, the axons showed impairedregenerationinmutantmice(Chen\&Strickland,2003). Peripheral nervesdevelopandfunction normally inGFAP-nullmice. However, axonal regeneration after crush lesion was delayed. Mutant Schwann cells maintained the ability to dedifferentiate but showed defective proliferation, a key event for successful nerve regeneration (Triolo et al., 2006). Neurofilament light knockout mice develop normally, but the regeneration of myelinated axons following crush injury was found to be abnormal with fewer newly regenerated myelinated axons in the sciatic nerve and facial nerve (Zhu, Couillard-Despres, \& Julien, 1997). BACE1 (b-site amyloid precursor protein cleaving enzyme 1) knockout and wild-type nerves degenerated at a similar rate after axotomy. However, BACE1 knockout mice had markedly enhanced clearance of axonal and myelin debris from degenerated fibers, accelerated axonal regeneration, and earlier reinnervation of NMJs, compared with controls (Farah et al., 2011). Fricker et al. (2011) used a single-neuron labeling with inducible Cremediated knockout animals, which enabled visualization of a subset of adult myelinated sensory and motoneurons in which Nrg1 was inducibly mutated by tamoxifen treatment. In uninjured mice, NRG1-deficient axons and the associated myelin sheath were normal, and the NMJ demonstrated normal apposition of presynaptic and postsynaptic components. After sciatic nerve crush, NRG1 ablation resulted in severe defects in remyelination: axons were either hypomyelinated or had no myelin sheath. NRG1-deficient axons were also found to regenerate at a slower rate (Fricker et al., 2011). Other studies use the overexpression of proteins in order to better understand the role of a certain protein and to circumvent methodological difficulties in drug delivery. For example, transgenic mice constitutively expressing both interleukin 6 (IL-6) and its receptor (IL-6R) showed accelerated regeneration of the axotomized nerve (Hirota, Kiyama, Kishimoto, \& Taga, 1996). The overexpression of FGF-2 showed no difference in number and size of myelinated fibers compared to wild-type mice in intact nerves. On the other hand, 1 week after crush injury, the number of regenerated axons was doubled and the myelin thickness was significantly smaller in transgenic mice, but after 2 and 4 weeks, there were no differences in the recovery of sensory and motor nerve fibers, showing that FGF-2 influences early peripheral nerve regeneration by regulating Schwanncell proliferation, axonal regrowth, and remyelination (Jungnickel, Haase, Konitzer, Timmer, \& Grothe, 2006). Transgenic mice expressing Nogo-C in peripheral Schwann cells regenerate axons less rapidly than do wild-type mice after mid-thigh 
sciatic nerve crush (Kim, Bonilla, Qiu, \& Strittmatter, 2003). On the other hand, using regulated transgenic expression of Nogo-A in peripheral nerve Schwann cells, Pot et al. (2002) showed that axonal regeneration and functional recovery are impaired after a sciatic nerve crush. Finally, the overexpression of L1(adhesion molecule) in neurons had no effect on femoral nerve function, numbers of quadriceps motoneurons, and myelinated axons in injured nerves; after femoral nerve injury, L1 overexpression had no impact on the time course and degree of functional recovery, but myelination in the motor and sensory femoral nerve branches was significantly improved and loss of perisomatic inhibitory terminals on motoneurons was attenuated in the transgenic mice (Guseva et al., 2011). Recently, we showed that constitutive ErbB2 receptor overexpression improves nerve regeneration following traumatic injury, possibly through the upregulation of soluble NRG1 isoforms (Ronchi et al., 2013).

\section{CONCLUSIONS}

Recent advances in peripheral nerve regeneration research have strengthened the view that the process of nerve regeneration and target reinnervation is quite complex and involves several factors. Keeping in mind the complexity of the whole process is thus very important for improving our knowledge on peripheral nerve regeneration, especially in the perspective of translating basic science results to the clinics. Figure 8.2 synthesizes this concept: in fact, it is important, but not enough, to study the involvement of a single molecule, such as the NRG1/ErbB system (Ronchi et al., 2013) or other ligands and receptors involving in the process. It is also important, but not enough, to study the cell-cell interaction (in particular the interaction between regenerating axons and glial cells). Moreover, it is important, but not enough, to study the dynamics of the regenerative nerve, for example, with a tissue engineering approach and reconstructive microsurgery. Rather, the wholesystemmust be taken intoaccount,including not only the damaged nerve and all the molecules involved in the process but also the proximal plasticity that occurs after a peripheral injury (DRG and CNS) and the effects that an injury has on distal sites (such as skeletal muscle atrophy). Methods to improve the regenerative process should therefore simultaneously potentiate axonal regeneration, increase neuronal survival, and modulate central reorganization, as well as reduce muscle and sensory receptor atrophy and degeneration. It is expected that this holistic approach might lead to significant improvement in the functional outcome and thus the quality of life of the patients suffering from peripheral nerve injury.

ACKNOWLEDGMENTS The research leading to this chapter has received funding from the European Community's Seventh Framework Programme (FP7-HEALTH-2011) under grant agreement no. 278612 (BIOHYBRID), from MIUR, and from Compagnia di San Paolo (MOVAG).

\section{REFERENCES}

Anand, P. (2004). Neurotrophic factors and their receptors in human sensory neuropathies. Progress in Brain Research, 146, 477-492. Anzini,P., Neuberg,D.H.,Schachner,M.,Nelles,E.,Willecke,K.,Zielasek,J.,etal.(1997). Structural abnormalities 
and deficient maintenance of peripheral nerve myelinin mice lacking the gap junction protein connexin32.TheJournalofNeuroscience,17(12),4545-4551.

Bain, J. R., Veltri, K. L., Chamberlain, D., \& Fahnestock, M. (2001). Improved functional recovery of denervated skeletal muscle after temporary sensory nerve innervation. Neuroscience, 103(2), 503-510.

Bannerman, P., Ara, J., Hahn, A., Hong, L., McCauley, E., Friesen, K., et al. (2008). Peripheral nerve regeneration is delayed in neuropilin 2-deficient mice. Journal of Neuroscience Research, 86(14), 3163-3169.

Baptista, A. F., Gomes, J. R., Oliveira, J. T., Santos, S. M., Vannier-Santos, M. A., \& Martinez, A. M. (2007). A new approach to assess function after sciatic nerve lesion in the mouse-Adaptation of the sciatic static index. Journal of Neuroscience Methods, 161(2), 259-264.

Battiston, B., Geuna, S., Ferrero, M., \& Tos, P. (2005). Nerve repair by means of tubulization: Literature review and personal clinical experience comparing biological and synthetic conduits for sensory nerve repair. Microsurgery, 25(4), 258-267.

Battiston, B., Raimondo, S., Tos, P., Gaidano, V., Audisio, C., Scevola, A., et al. (2009). Chapter 11: Tissue engineering of peripheral nerves. International Review of Neurobiology, 87, 227-249.

184 Pierluigi Tos et al.

Battiston, B., Tos, P., Cushway, T. R., \& Geuna, S. (2000). Nerve repair by means of vein filled with muscle grafts. I. Clinical results. Microsurgery, 20(1), 32-36.

Battiston, B., Tos, P., Geuna, S., Giacobini-Robecchi, M. G., \& Guglielmone, R. (2000). Nerve repair by means of vein filled with muscle grafts. II. Morphological analysis of regeneration. Microsurgery, 20(1), 37-41.

Biggio, F., Gorini, G., Utzeri, C., Olla, P., Marrosu, F., Mocchetti, I., et al. (2009). Chronic vagus nerve stimulation induces neuronal plasticity in the rat hippocampus. The International Journal of Neuropsychopharmacology, 12(9), 1209-1221. Birch, R., \& Raji, A. R. (1991). Repair of median and ulnar nerves. Primary suture is best. The Journal of Bone and Joint Surgery. British Volume, 73(1), 154-157.

Bruck, W. (1997). The role of macrophages in Wallerian degeneration. Brain Pathology, 7(2), 741752. Brunelli, G. (2005). Direct muscular neurotization. Journal of the American Society for Surgery of the Hand, 5(4), 193-200.

Brunelli, G. A., Battiston, B., Vigasio, A., Brunelli, G., \& Marocolo, D. (1993). Bridging nerve defects with combined skeletal muscle and vein conduits. Microsurgery, 14(4), 247-251.

Buchthal, F., \& Kuhl, V. (1979). Nerve conduction, tactile sensibility, and the electromyogram after suture or compression of peripheral nerve: A longitudinal study in man. Journal of Neurology, Neurosurgery, and Psychiatry, 42(5), 436-451.

Bungner, O. V. (1891). Ueber die degenerations und regenerations-Vorgange am Nerven nach Verletzungen. Beitrage zur Pathologischen Anatomie und zur Allgemeinen Pathologie, 10, 321. Burnett, M. G., \& Zager, E. L. (2004). Pathophysiology of peripheral nerve injury: A brief review. Neurosurgical Focus, 16(5), E1.

Carroll, S. L., Miller, M. L., Frohnert, P. W., Kim, S. S., \& Corbett, J. A. (1997). Expression of neuregulins and their putative receptors, ErbB2 and ErbB3, is induced during Wallerian degeneration. The Journal of Neuroscience, 17(5), 1642-1659. Chen, Z. L., \& Strickland, S. (2003). 
Laminin gamma1 is critical for Schwann cell differentiation, axon myelination, and regeneration in the peripheral nerve. The Journal of Cell Biology, 163(4), 889.

Chen, Z. L., Yu, W. M., \& Strickland, S. (2007). Peripheral regeneration. Annual Review of Neuroscience, 30, 209-233.

Coggeshall, R. E., Lekan, H. A., Doubell, T. P., Allchorne, A., \& Woolf, C. J. (1997). Central changes in primary afferent fibers following peripheral nerve lesions. Neuroscience, 77(4), 1115-1122.

Cohen, J. A., Yachnis, A. T., Arai, M., Davis, J. G., \& Scherer, S. S. (1992). Expression of the neu proto-oncogene by Schwann cells during peripheral nerve development and Wallerian degeneration. Journal of Neuroscience Research, 31(4), 622-634.

Corti, S., Locatelli, F., Papadimitriou, D., Donadoni, C., Del Bo, R., Crimi, M., et al. (2006). Transplanted ALDHhiSSClo neural stem cells generate motor neurons and delay disease progression of nmd mice, an animal model of SMARD1. Human Molecular Genetics, 15(2), 167187.

Corti, S., Nizzardo, M., Nardini, M., Donadoni, C., Salani, S., Ronchi, D., et al. (2009). Embryonic stem cell-derived neural stem cells improve spinal muscular atrophy phenotype in mice. Brain, 133(Pt. 2), 465-481.

Davis, K. D., Taylor, K. S., \& Anastakis, D. J. (2011). Nerve injury triggers changes in the brain. The Neuroscientist, 17(4), 407-422.

De Putter, C. E., Selles, R. W., Polinder, S., Panneman, M. J., Hovius, S. E., \& van Beeck, E. F. (2012). Economic impact of hand and wrist injuries: Health-care costs and productivity costs in a population-based study. The Journal of Bone and Joint Surgery. American Volume, 94(9), e56.

Deshpande, D. M., Kim, Y. S., Martinez, T., Carmen, J., Dike, S., Shats, I., et al. (2006). Recovery from paralysis in adult rats using embryonic stem cells. Annals of Neurology, 60(1), 32-44.

Donoghue, J. P., \& Sanes, J. N. (1987). Peripheral nerve injury in developing rats reorganizes representation pattern in motor cortex. Proceedings of the National Academy of Sciences of the United States of America, 84(4), 1123-1126.

Donoghue, J. P., \& Sanes, J. N. (1988). Organization of adult motor cortex representation patterns following neonatal forelimb nerve injury in rats. The Journal of Neuroscience, 8(9), 3221-3232.

Dvali, L., \&Mackinnon, S. (2003).Nerverepair, grafting, and nerve transfers. Clinics in Plastic Surgery, 30(2), 203-221.

Farah, M. H., Pan, B. H., Hoffman, P. N., Ferraris, D., Tsukamoto, T., Nguyen, T., et al. (2011). Reduced BACE1 activity enhances clearance of myelin debris and regeneration of axons in the injured peripheral nervous system. The Journal of Neuroscience, 31(15), 5744-5754. Fawcett, J. W., \& Keynes, R. J. (1990). Peripheral nerve regeneration. Annual Review of Neuroscience, 13, 4360.

Fenrich, K., \& Gordon, T. (2004). Canadian Association of Neuroscience review: Axonal regeneration in the peripheral and central nervous systems-Current issues and advances. The Canadian Journal of Neurological Sciences, 31(2), 142-156.

Fields, R. D., Le Beau, J. M., Longo, F. M., \& Ellisman, M. H. (1989). Nerve regeneration through artificial tubular implants. Progress in Neurobiology, 33(2), 87-134.

Finkelstein, D. I., Dooley, P. C., \& Luff, A. R. (1993). Recovery of muscle after different periods of denervation and treatments. Muscle \& Nerve, 16(7), 769-777. 
Follesa, P., Biggio, F., Gorini, G., Caria, S., Talani, G., Dazzi, L., et al. (2007). Vagus nerve stimulation increases norepinephrine concentration and the gene expression of BDNF and bFGF in the rat brain. Brain Research, 1179, 28-34.

Fornaro, M., Tos, P., Geuna, S., Giacobini-Robecchi, M. G., \& Battiston, B. (2001). Confocal imaging of Schwann-cell migration along muscle-vein combined grafts used to bridge nerve defects in the rat. Microsurgery, 21(4), 153-155.

Fricker, F. R., Lago, N., Balarajah, S., Tsantoulas, C., Tanna, S., Zhu, N., et al. (2011). Axonally derived neuregulin-1 is required for remyelination and regeneration after nerve injury in adulthood. The Journal of Neuroscience, 31(9), 3225-3233.

Fu, S. Y., \& Gordon, T. (1995). Contributing factors to poor functional recovery after delayed nerve repair: Prolonged denervation. The Journal of Neuroscience, 15(5 Pt. 2), 3886-3895.

Fullarton, A. C., Lenihan, D. V., Myles, L. M., \& Glasby, M. A. (2000). Obstetric brachial plexus palsy: A large animal model for traction injury and its repair. Part 1: Age of the recipient. Journal of Hand Surgery. British Volume, 25(1), 52-57.

Ganfornina, M. D., Do Carmo, S., Martinez, E., Tolivia, J., Navarro, A., Rassart, E., et al. (2010). $A p o D$, a glia-derived apolipoprotein, is required for peripheral nerve functional integrity and a timely response to injury. Glia, 58(11), 1320-1334.

Gao, J., Coggeshall, R. E., Tarasenko, Y. I., \& Wu, P. (2005). Human neural stem cell-derived cholinergic neurons innervate muscle in motoneuron deficient adult rats. Neuroscience, 131(2), 257-262.

Gao,W.Q.,Shinsky,N.,Armanini,M.P.,Moran,P.,Zheng,J.L.,Mendoza-Ramirez,J.L., et al. (1998). Regulation of hippocampal synaptic plasticity by the tyrosine kinase receptor, REK7/EphA5, and its ligand, AL-1/Ephrin-A5. Molecular and Cellular Neuroscience, 11(5-6), 247-259.

Geuna, S., Raimondo, S., Ronchi, G., Di Scipio, F., Tos, P., Czaja, K., et al. (2009). Chapter 3: Histology of the peripheral nerve and changes occurring during nerve regeneration. International Review of Neurobiology, 87, 27-46. 186 Pierluigi Tos et al.

Geuna, S., Tos, P., Raimondo, S., Lee, J. M., Gambarotta, G., Nicolino, S., et al. (2007). Functional, morphological and biomolecular assessment of posttraumatic neuromuscular recovery in the rat forelimb model. Acta Neurochirurgica. Supplement, 100, 173-177.

Glasby, M. A., Gschmeissner, S., Hitchcock, R. J., \& Huang, C. L. (1986). Regeneration of the sciatic nerve in rats. The effect of muscle basement membrane. The Journal of Bone and Joint Surgery. British Volume, 68(5), 829-833.

Griffin, J. W., \& Thompson, W. J. (2008). Biology and pathology of nonmyelinating Schwann cells. Glia, 56(14), 1518-1531.

Guseva, D., Zerwas, M., Xiao, M. F., Jakovcevski, I., Irintchev, A., \& Schachner, M. (2011). Adhesion molecule L1 overexpressed under the control of the neuronal Thy-1 promoter improves myelination after peripheral nerve injury in adult mice. Experimental Neurology, 229(2), 339-352.

Gutmann, E. (1962). Denervation and disuse atrophy in crosstriated muscle. Revue Canadienne de Biologie, 21, 353-365.

Haas, C. A., Donath, C., \& Kreutzberg, G. W. (1993). Differential expression of immediate early genes after transection of the facial nerve. Neuroscience, 53(1), 91-99. 
Hall, S. (2001). Nerve repair: A neurobiologist's view. Journal of Hand Surgery. British Volume, 26(2), 129-136.

Himes, B. T., \& Tessler, A. (1989). Death of some dorsal root ganglion neurons and plasticity of others following sciatic nerve section in adult and neonatal rats. The Journal of Comparative Neurology, 284(2), 215-230.

Hirota, H.,Kiyama, H., Kishimoto, T., \&Taga, T.(1996). Accelerated nerve regeneration in mice by upregulated expression of interleukin (IL) 6 and IL-6 receptor after trauma. The Journal of Experimental Medicine, 183(6), 2627-2634.

Hopkins, W. G., \& Slack, J. R. (1981). The sequential development of nodal sprouts in mouse muscles in response to nerve degeneration. Journal of Neurocytology, 10(4), 537-556.

Huang, J. K., Phillips, G. R., Roth, A. D., Pedraza, L., Shan, W., Belkaid, W., et al. (2005). Glial membranes at the node of Ranvier prevent neurite outgrowth. Science, 310(5755), 1813-1817.

Huelsenbeck, S. C., Rohrbeck, A., Handreck, A., Hellmich, G., Kiaei, E., Roettinger, I., et al. (2012). C3 peptide promotes axonal regeneration and functional motor recovery after peripheral nerve injury. Neurotherapeutics, 9(1), 185-198.

Hynes, N. M., Bain, J. R., Thoma, A., Veltri, K., \& Maguire, J. A. (1997). Preservation of denervated muscle by sensory protection in rats. Journal of Reconstructive Microsurgery, 13(5), 337-343. Ide, C. (1996). Peripheral nerve regeneration. Neuroscience Research, 25(2), 101-121.

Irintchev, A., Draguhn, A., \& Wernig, A. (1990). Reinnervation and recovery of mouse soleus muscle after long-term denervation. Neuroscience, 39(1), 231-243.

Jain, N., Florence, S. L., \& Kaas, J. H. (1998). Reorganization of somatosensory cortex after nerve and spinal cord injury. News in Physiological Sciences, 13, 143-149.

Jessen, K. R.,\&Mirsky, R.(2008). Negative regulation of myelination: Relevance for development, injury, and demyelinating disease. Glia, 56(14), 1552-1565.

Jungnickel, J., Haase, K., Konitzer, J., Timmer, M., \& Grothe, C. (2006). Faster nerve regeneration after sciatic nerve injury in mice over-expressing basic fibroblast growth factor. Journal of Neurobiology, 66(9), 940-948.

Kaas, J. H. (1991). Plasticity of sensory and motor maps in adult mammals. Annual Review of Neuroscience, 14, 137-167.

Kaas, J. H., \& Collins, C. E. (2003). Anatomic and functional reorganization of somatosensory cortex in mature primates after peripheral nerve and spinal cord injury. Advances in Neurology, 93, 8795.

Kandel, E. R.,\& Squire, L. R. (2000).Neuroscience: Breaking down scientific barriers to the study of brain and mind. Science, 290(5494), 1113-1120.

Keynes, R. J., Hopkins, W. G., \& Huang, L. H. (1984). Regeneration of mouse peripheral nerves in degenerating skeletal muscle: Guidance by residual muscle fibre basement membrane. Brain Research, 295(2), 275-281.

Kim, J. E., Bonilla, I. E., Qiu, D., \& Strittmatter, S. M. (2003). Nogo-C is sufficient to delay nerve regeneration. Molecular and Cellular Neuroscience, 23(3), 451-459.

Latres, E., Amini, A. R., Amini, A. A., Griffiths, J., Martin, F. J., Wei, Y., et al. (2005). Insulin-like growth factor-1 (IGF-1) inversely regulates atrophy-induced genes via the phosphatidylinositol 3- 
kinase/Akt/mammalian target of rapamycin (PI3K/Akt/ mTOR) pathway. The Journal of Biological Chemistry, 280(4), 2737-2744.

Leach, J. B., \& Schmidt, C. E. (2005). Characterization of protein release from photocrosslinkable hyaluronic acid-polyethylene glycol hydrogel tissue engineering scaffolds. Biomaterials, 26(2), 125-135.

Lee, J. P., Jeyakumar, M., Gonzalez, R., Takahashi, H., Lee, P. J., Baek, R. C., et al. (2007). Stem cells act through multiple mechanisms to benefit mice with neurodegenerative metabolic disease. Nature Medicine, 13(4), 439-447.

Lee, K. F., Li, E., Huber, L. J., Landis, S. C., Sharpe, A. H., Chao, M. V., et al. (1992). Targeted mutation of the gene encoding the low affinity NGF receptor $p 75$ leads to deficits in the peripheral sensory nervous system. Cell, 69(5), 737-749.

Lee, H. K., Shin, Y. K., Jung, J., Seo, S. Y., Baek, S. Y., \& Park, H. T. (2009). Proteasome inhibition suppresses Schwann cell dedifferentiation in vitro and in vivo. Glia, 57(16), 1825-1834.

Lee, J. M., Tos, P., Raimondo, S., Fornaro, M., Papalia, I., Geuna, S., et al. (2007). Lack of topographic specificity in nerve fiber regeneration of rat forelimb mixed nerves. Neuroscience, 144(3), 985-990. Letourneau, P. C., Condic, M. L., \& Snow, D. M. (1994). Interactions of developing neurons with the extracellular matrix. The Journal of Neuroscience, 14(3 Pt. 1), 915-928.

Lewin, G. R., \& McMahon, S. B. (1993). Muscle afferents innervating skin form somatotopically appropriate connections in the adult rat dorsal horn. The European Journal of Neuroscience, 5(8), 1083-1092.

Lieberman, A. R. (1971). The axon reaction: A review of the principal features of perikaryal responses to axon injury. International Review of Neurobiology, 14, 49-124.

Lu, D. X., Huang, S. K., \& Carlson, B. M. (1997). Electron microscopic study of long-term denervated rat skeletal muscle. The Anatomical Record, 248(3), 355-365.

Lubinska, L. (1982). Patterns of Wallerian degeneration of myelinated fibres in short and long peripheral stumps and in isolated segments of rat phrenic nerve. Interpretation of the role of axoplasmic flow of the trophic factor. Brain Research, 233(2), 227-240.

Luis, A. L., Amado, S., Geuna, S., Rodrigues, J. M., Simoes, M. J., Santos, J. D., et al. (2007). Longterm functional and morphological assessment of a standardized rat sciatic nerve crush injury with a non-serrated clamp. Journal of Neuroscience Methods, 163(1), 92-104.

Lundborg, G. (2000). A 25-year perspective of peripheral nerve surgery: Evolving neuroscientific concepts and clinical significance. Journal of Hand Surgery. American Volume, 25(3), 391-414.

Lundborg, G. (2003). Richard P. Bunge memorial lecture. Nerve injury and repair-A challenge to the plastic brain. Journal of the Peripheral Nervous System, 8(4), 209-226.

Lundborg, G. (2004). Alternatives to autologous nerve grafts. Handchirurgie, Mikrochirurgie, Plastische Chirurgie, 36(1), 1-7.

Lundborg, G. (2005). Nerve injury and repair: Regeneration, reconstruction, and cortical remodeling (2nd ed.). Philadelphia: Churchill Livingstone. Mackinnon, S. E. (1989). Newdirections inperipheral nerve surgery. Annals of Plastic Surgery, 22(3), 257-273.

188 Pierluigi Tos et al. 
McKay Hart, A., Brannstrom, T., Wiberg, M., \& Terenghi, G. (2002). Primary sensory neurons and satellite cells after peripheral axotomy in the adult rat: Timecourse of cell death and elimination. Experimental Brain Research, 142(3), 308-318.

McQuarrie, I. G. (1985). Effect of conditioning lesion on axonal sprout formation at nodes of Ranvier. The Journal of Comparative Neurology, 231(2), 239-249.

Merle, M., Bour, C., Foucher, G., \& Saint Laurent, Y. (1986). Sarcoid tenosynovitis in the hand. A case report and literature review. Journal of Hand Surgery. British Volume, 11(2), 281-286.

Merzenich, M. M., Kaas, J. H., Wall, J., Nelson, R. J., Sur, M., \& Felleman, D. (1983). Topographic reorganization of somatosensory cortical areas $3 b$ and 1 in adult monkeys following restricted deafferentation. Neuroscience, 8(1), 33-55.

Millesi, H. (1970). Problems in the reconstruction of extensive soft tissue defects in the upper extremeties. Handchirurgie, 2(2), 80-87.

Mizisin, A. P., Vu, Y., Shuff, M., \& Calcutt, N. A. (2004). Ciliary neurotrophic factor improves nerve conduction and ameliorates regeneration deficits in diabetic rats. Diabetes, 53(7), 1807-1812.

Navarro, X., Rodriguez, F. J., Labrador, R. O., Buti, M., Ceballos, D., Gomez, N., et al. (1996). Peripheral nerve regeneration through bioresorbable and durable nerve guides. Journal of the Peripheral Nervous System, 1(1), 53-64.

Navarro, X., Vivo, M., \& Valero-Cabre, A. (2007). Neural plasticity after peripheral nerve injury and regeneration. Progress in Neurobiology, 82(4), 163-201.

Ng, Y. P., Pun, S., Yang, J. F., Ip, N. Y., \& Tsim, K. W. (1997). Chick muscle expresses various ARIA isoforms: Regulation during development, denervation, and regeneration. Molecular and Cellular Neuroscience, 9(2), 132-143.

Nicolaidis, S. C., \& Williams, H. B. (2001). Muscle preservation using an implantable electrical system after nerve injury and repair. Microsurgery, 21(6), 241-247.

Nicolino, S., Panetto, A., Raimondo, S., Gambarotta, G., Guzzini, M., Fornaro, M., et al. (2009).Denervation and reinnervation of adult skeletal muscle modulate mRNA expression of neuregulin-1 and ErbB receptors. Microsurgery, 29(6), 464-472.

Papalia, I., Geuna, S., Tos, P. L., Boux, E., Battiston, B., \& Stagno D'Alcontres, F. (2003). Morphologic and functional study of rat median nerve repair by terminolateral neurorrhaphy of the ulnar nerve. Journal of Reconstructive Microsurgery, 19(4), 257-264.

Papalia, I., Tos, P., Scevola, A., Raimondo, S., \& Geuna, S. (2006). The ulnar test: A method forthe quantitative functional assessment of posttraumatic ulnar nerve recoveryin therat. Journal of Neuroscience Methods, 154(1-2), 198-203.

Papalia, I., Tos, P., Stagno d'Alcontres, F., Battiston, B., \& Geuna, S. (2003). On the use of the grasping test in the rat median nerve model: A re-appraisal of its efficacy for quantitative assessment of motor function recovery. Journal of Neuroscience Methods, 127(1), 43-47.

Pelled, G., Chuang, K. H., Dodd, S. J., \& Koretsky, A. P. (2007). Functional MRI detection of bilateral cortical reorganization in the rodent brain following peripheral nerve deafferentation. Neurolmage, 37(1), 262-273.

Pfister, B. J., Gordon, T., Loverde, J. R., Kochar, A. S., Mackinnon, S. E., \& Cullen, D. K. (2011). Biomedical engineering strategies for peripheral nerve repair: Surgical applications, state of the art, and future challenges. Critical Reviews in Biomedical Engineering, 39(2), 81-124. 
Pfister, L. A., Papaloizos, M., Merkle, H. P., \& Gander, B. (2007). Nerve conduits and growth factor delivery in peripheral nerve repair. Journal of the Peripheral Nervous System, 12(2), 65-82.

Porporato, P. E., Filigheddu, N., Reano, S., Ferrara, M., Angelino, E., Gnocchi, V. F., et al. (2013). Acylated and unacylated ghrelin impair skeletal muscle atrophy in mice. The Journal of Clinical Investigation, 123(2), 611-622.

Pot, C., Simonen, M., Weinmann, O., Schnell, L., Christ, F., Stoeckle, S., et al. (2002). Nogo-A expressed in Schwann cells impairs axonal regeneration after peripheral nerve injury. The Journal of Cell Biology, 159(1), 29-35.

Ronchi, G., Gambarotta, G., Di Scipio, F., Salamone, P., Sprio, A. E., Cavallo, F., et al. (2013). ErbB2 receptor over-expression improves post-traumatic peripheral nerve regeneration in adult mice. PLoS One, 8(2), e56282.

Ronchi, G., Ryu, V., Fornaro, M., \& Czaja, K. (2012). Hippocampal plasticity after a vagus nerve injury in the rat. Neural Regeneration Research, 7(14), 1055-1063.

Sanes, J. N., Suner, S., \& Donoghue, J. P. (1990). Dynamic organization of primary motor cortex output to target muscles in adult rats. I. Long-term patterns of reorganization following motor or mixed peripheral nerve lesions. Experimental Brain Research, 79(3), 479-491.

Schlaepfer, W. W. (1977). Structural alterations of peripheral nerve induced by the calcium ionophore A23187. Brain Research, 136(1), 1-9.

Schmalbruch, H., al-Amood, W. S., \& Lewis, D. M. (1991). Morphology of long-term denervated rat soleus muscle and the effect of chronic electrical stimulation. The Journal of Physiology, 441, 233241.

Schmidt, C. E., \& Leach, J. B. (2003). Neural tissue engineering: Strategies for repair and regeneration. Annual Review of Biomedical Engineering, 5, 293-347.

Scholz, T., Krichevsky, A., Sumarto, A., Jaffurs, D., Wirth, G. A., Paydar, K., et al. (2009). Peripheral nerve injuries: An international survey of current treatments and future perspectives. Journal of Reconstructive Microsurgery, 25(6), 339-344.

Schultz, E., Jaryszak, D. L., \& Valliere, C. R. (1985). Response of satellite cells to focal skeletal muscle injury. Muscle \& Nerve, 8(3), 217-222.

Seddon, H. (1943). Three types of nerve injury. Brain, 66, 237-288. Seddon, B., \& Fynn, G. H. (1972). Cation activated hydrolysis of ATP by the soluble fraction of Bacillus brevis. Microbios, 6(22), 87-96.

Shen,Z.L.,Lassner,F.,Bader,A.,Becker,M.,Walter,G.F.,\&Berger,A.(2000).Cellularactivity of resident macrophages during Wallerian degeneration. Microsurgery, 20(5), 255-261.

Sinis, N., Guntinas-Lichius, O., Irintchev, A., Skouras, E., Kuerten, S., Pavlov, S. P., et al. (2008). Manual stimulation of forearm muscles does not improve recovery of motor function after injury to a mixed peripheral nerve. Experimental Brain Research, 185(3), 469-483.

Stoll, G., Griffin, J. W., Li, C. Y., \& Trapp, B. D. (1989). Wallerian degeneration in the peripheral nervous system: Participation of both Schwann cells and macrophages in myelin degradation. Journal of Neurocytology, 18(5), 671-683.

Stoll, G., Jander, S., \& Myers, R. R. (2002). Degeneration and regeneration of the peripheral nervous system: From Augustus Waller's observations to neuroinflammation. Journal of the Peripheral Nervous System, 7(1), 13-27. 
Suarez, E., Bach, D., Cadefau, J., Palacin, M., Zorzano, A., \& Guma, A. (2001). A novel role of neuregulin in skeletal muscle. Neuregulin stimulates glucose uptake, glucose transporter translocation, and transporter expression in muscle cells. The Journal of Biological Chemistry, 276(21), 18257-18264.

Sun, W., Sun, C., Zhao, H., Lin, H., Han, Q., Wang, J., et al. (2009). Improvement of sciatic nerve regeneration using laminin-binding human NGF-beta. PLoS One, 4(7), e6180.

Sunderland, S. (1951). A classification of peripheral nerve injuries producing loss of function. Brain, 74(4), 491-516.

Swett, J. E., Hong, C. Z., \& Miller, P. G. (1995). Most dorsal root ganglion neurons of the adult rat survive nerve crush injury. Somatosensory and Motor Research, 12(3-4), 177-189.

Tang, H., Cheung, W. M., Ip, F. C., \& Ip, N. Y. (2000). Identification and characterization of differentially expressed genes in denervated muscle. Molecular and Cellular Neuroscience, 16(2), 127-140.

Terenghi, G. (1999). Peripheral nerve regeneration and neurotrophic factors. Journal of Anatomy, 194(Pt. 1), 1-14.

Terzis, J. K., Sun, D. D., \& Thanos, P. K. (1997). Historical and basic science review: Past, present, and future of nerve repair. Journal of Reconstructive Microsurgery, 13(3), 215-225.

Tetzlaff, W., Gilad, V. H., Leonard, C., Bisby, M. A., \& Gilad, G. M. (1988). Retrograde changes in transglutaminase activity after peripheral nerve injuries. Brain Research, 445(1), 142-146.

Tos, P., Battiston, B., Ciclamini, D., Geuna, S., \& Artiaco, S. (2012). Primary repair of crush nerve injuries by means of biological tubulization with muscle-vein-combined grafts. Microsurgery, 32(5), 358-363.

Tos, P., Battiston, B., Nicolino, S., Raimondo, S., Fornaro, M., Lee, J. M., et al. (2007). Comparison of fresh and predegenerated muscle-vein-combined guides for the repair of rat median nerve. Microsurgery, 27(1), 48-55.

Tos, P., Ronchi, G., Nicolino, S., Audisio, C., Raimondo, S., Fornaro, M., et al. (2008). Employment of the mouse median nerve model for the experimental assessment of peripheral nerve regeneration. Journal of Neuroscience Methods, 169(1), 119-127.

Tos, P., Ronchi, G., Papalia, I., Sallen, V., Legagneux, J., Geuna, S., et al. (2009). Chapter 4: Methods and protocols in peripheral nerve regeneration experimental research: Part I- Experimental models. International Review of Neurobiology, 87, 47-79.

Trapp, B. D., Hauer, P., \& Lemke, G. (1988). Axonal regulation of myelin protein mRNA levels in actively myelinating Schwann cells. The Journal of Neuroscience, 8(9), 3515-3521.

Triolo, D., Dina, G., Lorenzetti, I., Malaguti, M., Morana, P., Del Carro, U., et al. (2006). Loss of glial fibrillary acidic protein (GFAP) impairs Schwann cell proliferation and delays nerve regeneration after damage. Journal of Cell Science, 119(Pt. 19), 3981-3993.

Varejao, A. S., Cabrita, A. M., Meek, M. F., Bulas-Cruz, J., Melo-Pinto, P., Raimondo, S., et al. (2004). Functional and morphological assessment of a standardized rat sciatic nerve crush injury with a non-serrated clamp. Journal of Neurotrauma, 21(11), 1652-1670.

Vargas, M. E., \& Barres, B. A. (2007). Why is Wallerian degeneration in the CNS so slow? Annual Review of Neuroscience, 30, 153-179. Veltri, K., Kwiecien, J. M., Minet, W., Fahnestock, M., \& Bain, J. R. (2005). Contribution of the distal nerve sheath to nerve and muscle preservation 
following denervation and sensory protection. Journal of Reconstructive Microsurgery, 21(1), 5770, discussion 71-54.

Vestergaard, S., Tandrup, T., \& Jakobsen, J. (1997). Effect of permanent axotomy on number and volume of dorsal root ganglion cell bodies. The Journal of Comparative Neurology, 388(2), 307312. Vial, J. D. (1958). The early changes in the axoplasm during Wallerian degeneration. The Journal of Biophysical and Biochemical Cytology, 4(5), 551-555.

Wall, J. T., Xu, J., \& Wang, X. (2002). Human brain plasticity: An emerging view of the multiple substrates and mechanisms that cause cortical changes and related sensory dysfunctions after injuries of sensory inputs from the body. Brain Research. Brain Research Reviews, 39(2-3), 181215.

Wang, H., Gu, Y., Xu, J., Shen, L., \& Li, J. (2001). Comparative study of different surgical procedures using sensory nerves or neurons for delaying atrophy of denervated skeletal muscle. Journal of Hand Surgery. American Volume, 26(2), 326-331.

White, F. V., Toews, A. D., Goodrum, J. F., Novicki, D. L., Bouldin, T. W., \& Morell, P. (1989). Lipid metabolism during early stages of Wallerian degeneration in the rat sciatic nerve. Journal of Neurochemistry, 52(4), 1085-1092.

Wrede, L. (1909). Uberbrueckung eines Nervendefektes mittels Seidennahtund leben Venenstueckes. Deutsche Medizinische Wochenschrift, 35, 1125-1160.

Yamaguchi, A., Ishii, H., Morita, I., Oota, I., \& Takeda, H. (2004). mRNA expression of fibroblast growth factors and hepatocyte growth factor in rat plantaris muscle following denervation and compensatory overload. Pflu "gers Archiv, 448(5), 539-546.

Yannas, I. V., \& Hill, B. J. (2004). Selection of biomaterials for peripheral nerve regeneration using data from the nerve chamber model. Biomaterials, 25(9), 1593-1600.

Yoshida, T., Semprun-Prieto, L., Sukhanov, S., \& Delafontaine, P. (2010). IGF-1 prevents ANG IIinduced skeletal muscle atrophy via Akt- and Foxo-dependent inhibition of the ubiquitin ligase atrogin-1 expression. American Journal of Physiology. Heart and Circulatory Physiology, 298(5), H1565-H1570.

Young, R. C., Wiberg, M., \& Terenghi, G. (2002). Poly-3-hydroxybutyrate (PHB): A resorbable conduit for long-gap repair in peripheral nerves. British Journal of Plastic Surgery, 55(3), 235-240. Zhao, C., Veltri, K., Li, S., Bain, J. R., \& Fahnestock, M. (2004). NGF, BDNF, NT-3, and GDNF mRNA expression in rat skeletal muscle following denervation and sensory protection. Journal of Neurotrauma, 21(10), 1468-1478.

Zhu, Q., Couillard-Despres, S., \& Julien, J. P. (1997). Delayed maturation of regenerating myelinated axons in mice lacking neurofilaments. Experimental Neurology, 148(1), 299-316. 